https://doi.org/10.46344/JBINO.2021.v10i2b.15

\title{
IS IT TIME FOR AYURVEDA TO REINVENT AND REPURPOSE ITSELF?
}

\section{Dr Aakash Kembhavi \& Dr Anita Kadagad Kembhavi,}

Directors, Astanga Wellness Pvt Ltd, Hubli, Karnataka, India

\section{ABSTRACT}

COVID-19 remains a global disaster. Worse, it was a preventable disaster. A World Health Organization official said that it is reclassifying the highly contagious triple-mutant Covid variant spreading in India as a "variant of concern," indicating that it's become a global health threat. Every healthcare system is stretched to the limit and the coming days are going to be a challenge that will test the Indian Healthcare infrastructure and personnel unlike any other time in history as can be understood by Dr Devi Shetty's statement. Amidst all these developments, we have to question the role of Ayurveda in the management of Covid 19 and its varied clinical presentations. Though these efforts have been initiated and widely promoted, the ground reality remains that there is a lot of confusion whether the state governments have allowed Ayurveda practitioners to treat Covid 19 cases officially. However, many vaidyas across India are managing mild, moderate and even severe cases of Covid 19 very effectively with encouraging results. Our concern is that the system of Ayurveda is not qualified to be a front runner in addressing the issues of such magnitude as a professional body of experts. What the Covid -19 pandemic has exposed is the lack of co-ordination in the healthcare system of our country and more so in the field of Ayurveda. There is no platform through which Ayurveda doctors can share their data in real time. There is no doubt that Ayurveda has the answers to many of the diseases plaguing mankind. Decades of work by eminent physicians has proved this. The problem is that of documentation and this is the root cause of all the controversies and questions about its efficacy and validity. Thus the question: Is it time for Ayurveda to Repurpose Itself?

Key Words: Ayurveda, Covid-19, Research, Ayush 


\section{Introduction}

That is why the recommendations of the Independent Panel for Pandemic Preparedness and Response are urgent and vital. The world needs a new international system for pandemic preparedness and response, and it needs one fast, to stop future infectious disease outbreaks from becoming catastrophic pandemics. The Independent Panel has found weak links at every point in the chain of preparedness and response. Preparation was inconsistent and underfunded. The alert system was too slow-and too meek. The World Health Organization was under-powered. The response has exacerbated inequalities. Global political leadership was absent. Now, a priority is to end illness and deaths from COVID-19. Current national waves of transmission are causing the same human traumas as those witnessed last year-especially tragic when we know that public health measures could prevent them. Vaccine distribution is blatantly unjust and not strategic. Vaccine variants are emerging as SARSCoV-2 spreads, and ever new ones are possible. The burden on people and nations is intolerable. That is why the Panel calls for essential short-term measures. But the world cannot afford to focus only on COVID-19. It must learn from this crisis, and plan for the next one. Otherwise, precious time and momentum will be lost. That is why our recommendations focus on the future. COVID-19 has been a terrible wake-up call. So now the world needs to wake up, and commit to clear targets, additional resources, new measures and strong leadership to prepare for the future. We have been warned. (1)
This report summary is a transparent, honest and evidence based assessment of how things went wrong and what could have been done by all the countries and their healthcare systems to either avert or prevent the scale of disaster that is unfolding even today. Absence of credible leadership is an understatement. Ignorance of data and decisions not based on scientific evidence and advice has landed us in this mayhem. That the clinical protocols are still emerging is proof that we have still not completely understood the virus completely. "Variants of Concern" (2) are emerging and spreading all over the world. A World Health Organization official said that it is reclassifying the highly contagious triple-mutant Covid variant spreading in India as a "variant of concern," indicating that it's become a global health threat.(3) Models of predicting(4) the subsequent waves of the pandemic though frightening should serve as the basis of decision making.

Every healthcare system is stretched to the limit and the coming days are going to be a challenge that will test the Indian Healthcare infrastructure and personnel unlike any other time in history as can be understood by Dr Devi Shetty's statement. (5)

\section{Ayush and Ayurveda:}

Amidst all these developments, we have to question the role of Ayurveda in the management of Covid 19 and its varied clinical presentations. Ayurveda is regulated by the Ministry of Ayush and since the pandemic began, it has taken quite a few initiatives to address the challenges. (6)

The Ministry of Ayush issued Advisory (7) Ayurveda Immunity boosting measures 
(8), National Clinical Management protocol (9), Constitution of Interdisciplinary Ayush Research and Development Task force on 2nd April 2020 (10), Guidelines for Ayurveda \& Unani Practitioners for COVID-19 Patients in Home Isolation and Ayurveda \& Unani Preventive Measures for self care during COVID-19 Pandemic on 26th April 2021 (11), Revised National Clinical Management Protocol based on Ayurveda and Yoga for management of Covid-19 (12), FIRST REPORT AND RECOMMENDATIONS of Interdisciplinary Committee for integration of Ayurveda and Yoga Interventions in the 'National Clinical Management Protocol: COVID19' (OM No. A. 17020/1/2020-E.I dated 16th July 2020, Ministry of AYUSH, Govt. of India (13), Order to stop and prevent publicity and advertisement of Ayush related claims for Covid-19 treatment - F. No. Z 25023 /09/2018-2020-DCC (AYUSH) Government of India Ministry of Ayurveda, Yoga \& Naturopathy, Unani, Siddha and Homoeopathy (AYUSH) Dated: 1st April, 2020.(14)

Ayush 64 (15), a poly herbal formulation which was tried and found effective in the management of mild to moderate Covid 19 cases was recently released nationwide on the 10th of May 2021. (16)

Though these efforts have been initiated and widely promoted, the ground reality remains that there is a lot of confusion whether the state governments have allowed Ayurveda practitioners to treat Covid 19 cases officially. However, many vaidyas across India are managing mild, moderate and even severe cases of Covid 19 very effectively with encouraging results. What this translates into is that Ayurveda is able to prevent hospitalisations and therefore effective in preventing the burden on the stretched infrastructure of the hospitals. The downside is that none of these are proved through clinical trials and this highlights the failure of the system to provide a platform and support to these vaidyas where they can showcase their results. Although, all the vaidyas have been asked to submit their data to the Ministry for review by the expert panel, it remains doubtful if this is actually done by the vaidyas.

\section{Our Concerns:}

Our concern is that the system of Ayurveda is not qualified to be a front runner in addressing the issues of such magnitude as a professional body of experts. Though Ayurveda is a bodymind-spirit science and the texts and scriptures describe all aspects of health and disease in extensive detail right from daily to the seasonal regimens, dietary rules and regulations, causative factors of diseases including pandemics and an armoury of treatment options that is unrivalled, it has not yet been completely successful in proving itself as a credible form of treatment option. It has its own limitations. One may argue that the modern methods of scientific clinical trials cannot be applied to prove Ayurveda. There is also a growing number of people in Ayurveda who are of the opinion that "we do not need to prove anything to anybody" and "Ayurveda is beyond these research methods and statistical calculations".

Another dimension of these developments is the discussion on various Ayurveda WhatsApp groups about the questionable evidences for the 
recommendation of Remdesivir, Vaccines etc and that the pharma lobbies are controlling the developments and not allowing Ayurveda to become main stream.

The pandemic has exposed the fragile healthcare system not only in India but in other countries around the world as well. That decisions taken based on scientific evidence and correct data yield better outcomes cannot be stressed much. The problem is with the quality of data coming out. All the scientists and epidemiologists are demanding robust, transparent and unadulterated data in order to make sense of the chaos that we are in.

What is required is a robust system for capturing the data. Universal reporting software is the bare minimum required to keep track of these events. An integrated electronic health records management system is the need of the hour. Like the one used by the NHS in England (17) or the hybrid system (18) of the United States of America, we need a healthcare system that connects the length and breadth of India.

\section{Reality:}

The problem with Ayurveda is that uniformity is frowned upon saying that it is a personalised medicine and every Ayurveda doctor uses his/her method of data collection. But even a cursory look at the principles of Ayurveda described in the sacred texts of Ayurveda will reveal that there is a common platform to assess and capture data of all patients irrespective of their diseases. Too many egos and a patriarchal mindset have not allowed for even standardising the case proforma to collect data. Data analysis comes only after data capture.
Interestingly though the Ministry of Ayush in its minimum standards requirements for each Ayurveda college \& hospital mandates that a minimum of 140 to 150 patients have to be recorded in OPD and a minimum of $50 \%$ bed occupancy should be maintained in the OPD. The reality is that a vast majority of Ayurveda colleges do not have an input of more than 50 to 60 patients per day which means that in order to qualify for the affiliation and permission to continue, these colleges literally "cook" data to match the required numbers. And to make matters worse, there is no software which is officially recommended by the authorities to capture the data. So, the integrity of data generated in Ayurveda colleges and hospitals is of questionable value. Even the vast majority of independent practitioners of Ayurveda do not use any software to collect the patient data. Therefore, at any given point of time, we do not have the data of either the incidence or prevalence of a given disease from an Ayurvedic perspective.

"Prakruti" analysis, that can be roughly translated as "individual personality trait" is heavily popularised as the mainstay of Ayurveda approach, but, it remains a fact that there is no data available about the prakruti of our people.

Ayurveda describes diseases based on Vata, Pitta and Kapha varieties either singly or in various permutations and combinations of these three bodily humors called as "dosha". The Ministry of AYUSH has developed National Ayurveda Morbidity Codes (NAMC), comprehensive classification of diseases described in Ayurveda as well as Standardized Ayurveda Terminologies. 2021 April - May Special Edition | www.jbino.com | Innovative Association 
These have been made available on National AYUSH Morbidity and Standardized Terminologies Electronic Portal (NAMASTE Portal) developed by the Ministry which is available to the public on the URL(19)

NAMASTE - PORTAL is an acronym for "National Ayush Morbidity and Standardized Terminologies Electronic Portal". (20)

\section{It's Objectives are:}

1. The portal provides Standardized Terminologies \& Morbidity Codes for Ayurveda, Siddha and Unani systems of medicine along with W.H.O ICD-10/11 codes meant for dual coding and morbidity reporting for Yoga, Naturopathy and Homoeopathy Systems.

2. These are meant for unambiguous reporting, electronic data submission through individual institutions and gradually moving towards adopting Electronic Health Records (E.H.R.).

The stated objectives seem to be a step in the right direction. The challenge is in the implementation and acceptance of these codes by the Ayurveda fraternity.

\section{Ayurveda and Pandemic Preparedness:}

What the Covid -19 pandemic has exposed is the lack of co-ordination in the healthcare system of our country and more so in the field of Ayurveda. There is no platform through which Ayurveda doctors can share their data in real time. The WHO pandemic preparedness guide says - "The operational readiness categorization was refined based on additional information from voluntary external evaluations, pandemic influenza preparedness plans, country readiness assessment for health emergencies, missions to the countries, as well as the most up-to-date country specific COVID-
19 situation analyses. This categorization is updated regularly based on the evolving COVID-19 situation in each country and specific country risk and capacity assessments which will be conducted to identify key response requirements as the situation evolves." (21) A new Strategic Preparedness and Response plan was released in Feb 2021 to counter the new variants emerging in different countries. The role of traditional medicine has been very clearly highlighted by the WHO in the response plan for Covid -19. (22) Ayurveda should have activated its own response plan with immediate effect based on those guidelines. Though it did, there exist a lot of confusion and lack of co-ordination at all levels. There is a clear lack of a system which is standing up and responding to the humanitarian crisis that we are facing. Individual vaidyas are left to fend for themselves and a majority of them are doing so with great credibility. It would have been much better if Ayurveda as a system would have been doing it.

The role of the following experts is very crucial in times of an emerging pandemic to help take real time decisions and promote effective communication:

1. Clinical Specialists

2. Pathologists

3. Epidemiologists

4. Virologists

5. Data Analysts

6. Scientific modellers

It goes without saying that a data capturing tool is a pre-requisite.

\section{Challenges that Ayurveda should immediately address:}

The problem is that Ayurveda has only clinical specialists and the other experts are non-existent. Why? Because, we have 
never felt the need to develop these experts in Ayurveda all these years. Though there are 22 disciplines of post graduate studies in Ayurveda, the focus is clearly missing on creating professionals in developing a national healthcare system. (23) The quality of vast majority of research done at these post graduate institutes is questionable. There are no standardised guidelines even for submitting a synopsis for a proposed research activity. The institutional ethical committees are constituted only on paper to fulfil the formality. There is no body to recognise and regulate these committees. Thousands of research dissertations are submitted every year which have poor scientific value and most of them are copy-paste versions of previously submitted works. Plagiarism is rampant and there is no acknowledgement of the same. The topics selected for research do not reflect the public healthcare needs of the society as there is no body which gives directions or regulates this most important aspect of research.

Clinical exposure during the under graduate and post graduate studies is very minimal in a vast majority of Ayurveda institutions and the level of clinical competence of many graduating Ayurveda doctors in treating diseases with Ayurveda protocols is very poor. This issue has been discussed in another paper published by the authors titled Reforms in Ayurveda Education: Challenges and Roadblocks. (24)

It is high time that a strategy is developed and initiated with immediate effect to develop these domain experts in Ayurveda into a professional body of healthcare experts.

\section{Proposed solutions:}

1. Realignment of the core curriculum of both undergraduate and post graduate studies to reflect the current needs of the society

2. Introduce uniform teaching methods across the country and train the teachers to teach clinical competency using problem based learning techniques rather than rote learning

3. Set up Zonal and National level Ayurveda Research Centres and an Ayurveda Research laboratories

4. Introduce a uniform clinical data capturing software which should be mandatorily used by all Ayurveda colleges, hospitals and practitioners

5. Set up Zonal and National level data collection centres

6. Set up an Ayurveda Diseases Surveillance centre

7. Train Ayurveda doctors to be epidemiologists to enable them to study trends in the society

8. Develop a team of clinical experts from all domains so that they can recommend strategies and responses to the information passed on by the epidemiologists

9. Integrate Artificial Intelligence specialists and data analysts into our system who will specifically study Ayurveda data

The authors have published a paper titled - Does Ayurveda qualify as a public healthcare system? (25) where they discuss the shortcomings in Ayurveda as a system of professionals.

\section{Discussion and Conclusion:}

There is no dearth of talent in Ayurveda. The issue is one of a vision which is lacking to develop Ayurveda as a robust, scientific and reliable system of individual and public healthcare system. 
Since the pandemic began last year and as recently as yesterday, the 23rd May 2021, Sri Narendra Nayak, President of Federation of Indian rationalist Associations has been very vocal about his views on the Ayush Ministry guidelines for Covid-19, and has even said that "quackery" is being promoted in the name of Ayush treatments for Covid-19 (26) and has argued as to why the push for Ayush is harmful during this pandemic. (27)

Ayurveda as a system cannot afford to respond with a knee jerk reaction to such arguments. Instead, it should be taken in sportingly and should counteract with evidences to prove such statements wrong. Blaming allopathy or the modern scientific world for not allowing Ayurveda to be used is a futile exercise. Unless we represent our system professionally and unitedly in providing data which is scientific evidence to either prevent of tackle the symptoms of Covid-19, there will always be questions asked.

Another argument used by the Ayurveda fraternity is about the changing protocols of modern medicine in treating Covid-19. What we need to understand is that in a new and emerging disease pattern it is impossible to develop a treatment protocol quickly and the disease has to be fought with available knowledge and resources. As clinical evidence from studies across the world starts coming in, in real time the protocol keeps developing and gets refined. This should not be seen as a failure of the modern medicine but rather as a progressive science which accepts its limitations and is keen to point out the flaws in its past approaches and remove them from the protocol.
These are the questions that come to our mind:

1. What prevented Ayurveda as a system to conduct a clinical trial and come out with its own data?

2. When hundreds of clinical studies have been done across the world on thousands of patients, why then a robust clinical study not initiated and if so, where are the results and evidences?

3. Why is it taking so long to publish the results?

Given that we have an independent ministry and a minister and Ayurveda professionals who are at the helm of affairs, it is rather inconceivable that a multi-centric Ayurveda clinical trial could not have been designed and done by this time. Time is of the essence here and we should have come out with some answers. The social media is abuzz with personal experiences of many Ayurveda vaidyas across the country that has successfully treated mild, moderate and even severe cases of Covid-19 cases. Patient testimonials too are being shared. Why then are there not a concerted effort and a voice that supports these people?

The recent events in Andhra Pradesh where a local traditional healer was prevented from distributing medicines which was touted as a "miracle cure" to treat Covid-19 cases and the ICMR was instructed to study the efficacy as claimed, highlight the fact that in India, faith in local healers is not based on facts but by word of mouth experiences shared by people. (28) There were contrasting opinions within the Ayurveda fraternity about this incident. While some supported the decision that it needs scientific validation, a majority of the 
vaidyas started sharing supportive evidences for the ingredients used in the remedy. Another strong opinion that was gathering support was the view that ICMR will definitely botch up the study and conclude that the remedy is useless or not recommend it for use in Covid-19. The role of the strong pharma lobby is also being cited as a reason that this is happening. Some claim that the allopathic doctors are worried that their incomes will dwindle if such a remedy is recommended and therefore they are lobbying against it. Though past experiences and the way Ayurveda has been treated so far may be the underlying cause of concern amongst the Ayurveda vaidyas, one fact that emerges is that there is still a long way to go in so far as developing a scientific temper amongst the Ayurveda fraternity. Neither the system of Ayurveda has its own scientific laboratories to conduct a robust research nor does it believe in the ones that do.

There is a huge scope in Ayurveda to develop its independent research methodology and analytical tools to evaluate the research protocols based on its principles but it does not mean that it should discard the principles of research existing now. The present knowledge can be used as a stepping stone to develop its own methodology. The Equator guidelines (29) are a great place to start and are in fact being recommended by journals publishing Ayurveda researches.

There is no doubt that Ayurveda has the answers to many of the diseases plaguing mankind. Decades of work by eminent physicians has proved this. The problem is that of documentation and this is the root cause of all the controversies and questions about its efficacy and validity. The authors are of the opinion that there is a huge database of knowledge in modern science and it is only apt that Ayurveda digs into it, learns and develops into a robust science which will stand the test of time for generations to follow. It is the responsibility of people within the system to recognise this need and reach out to experts in other domains to build Ayurveda from here on. Acharya Sushruta, Caraka and Vaghbata would be more than happy if this happens because right now they are not lying comfortably in their graves and everytime someone questions the validity of Ayurveda, their spirit gets dampened because we as a system are not standing up to support our own cause. They surely must be questioning the integrity of the people running Ayurveda and the vaidyas practising it because, this is not the status that they must have envisioned for a science which they systematically developed, nurtured, propagated and nourished.

Will we ever be able to do justice for their vision? We can if we try to repurpose Ayurveda to meet the challenges of the present day clinical context be it the pandemic or other aspects of public healthcare.

\section{Conflict of Interest: Nil \\ Funding: Nil \\ References:}

1. https://theindependentpanel.org/docum ents/

2. https://www.cnbc.com/2021/05/11/indiacovid-explainer-what-we-know-aboutthe-bpointlpoint617-variant.html

3. https://www.cnbc.com/2021/05/10/whoclassifies-triple-mutant-covid-variant-fromindia-as-global-health-risk-.html 
4. https://theconversation.com/how-tomodel-a-pandemic-134187

5. https://indianexpress.com/article/india/la ck-of-doctors-and-nurses-to-treat-covidpatients-will-be-the-next-big-crisis-dr-devishetty-7298066/ accessed on the $13^{\text {th }}$ of May 2021

6. https://health.ncog.gov.in/ayush-coviddashbaord/

7. https://health.ncog.gov.in/ayush-coviddashbaord/assets/Classified/ADVISORY F ROM_MINISTRY_OF_AYUSH_FOR_MEETING THE_CHALLENGE_ARISING_OUT_OF_SPRE AD_OF_CORONA_VIRUS_(C.pdf),

8. https://health.ncog.gov.in/ayush-coviddashbaord/assets/Classified/Ayurveda i mmunity_boosting measures_for_self_car e_during_COVID_19_crisis.pdf

9. https://health.ncog.gov.in/ayush-coviddashbaord/assets/Classified/National clin ical_Management_Protocol.pdf

10.https://health.ncog.gov.in/ayush-coviddashbaord/assets/Classified/Constitution. of Interdisciplinary Ayush Research and Development_Task_Force 1.pdf

11.https://www.ayush.gov.in/docs/Note\%20 on\%20Ayush\%20Guidelines\%2026\%20April\%202021.pdf

12. https://www.ayush.gov.in/docs/faqcovid-protocol-Revised.pdf

13. https://www.ayush.gov.in/docs/Report\%2 Oand\%20Recommendations\%200f\%20Inte rdisciplinary\%20Committee.pdf

14. https://www.ayush.gov.in/docs/121.pdf .

15. https://www.ayush.gov.in/docs/Ayush123 . $\mathrm{pdf}$

16. https://www.moneycontrol.com/news/co ronavirus/free-distribution-of-ayush-64-allyou-need-to-know-about-the-ayurvedicdrug-to-treat-covid-6876401.html

17. https://www.england.nhs.uk/digitaltechn ology/connecteddigitalsystems/
18. https://www.dpeaflcio.org/factsheets/th e-us-health-care-system-an-internationalperspective,

19. http://namstp.ayush.gov.in. (https://pib.gov.in/Pressreleaseshare.aspx ?PRID $=1605616$ )

20. https://vajiramias.com/currentaffairs/namasteportal/5c322ff320993742be51ba60/

21. https://www.who.int/publications/i/item/ updated-country-preparedness-andresponse-status-for-covid-19-as-of-9-june$\underline{2020}$

22. https://www.who.int/publications/i/item/ WHO-WHE-2021.02

23. https://main.ayush.gov.in/sites/default/fil es/6729652177-

Regular\%20Courses\%20available\%20in\%2 OAyurveda_0_0.pdf

24. https://doi.org/10.23880/jonam-16000224 25. http://www.armarc.in/does-ayurvedaqualify-as-a-public-healthcare-system/

26. https://timesofindia.indiatimes.com/city/ mangaluru/rationalists-decry-centresadvisory-oncoronavirus/articleshow/73779802.cms

27. https://www.thenewsminute.com/article/ why-push-ayush-harmful-narendra-nayakinterview-149330

28. https://www.businessstandard.com/article/currentaffairs/ayurvedic-medicine-touted-asmiracle-cure-for-covid-19-to-be-sent-toicmr-121052101088_1.html

29. https://www.equator-network.org/ 